Madrygal. Revista de Estudios Gallegos

ISSN: 1138-9664

\title{
A memoria da mina de Varilongo (Santa Comba)
}

\author{
Carmen Blanco Ramos ${ }^{1}$
}

13 de xuño de 2019 / Aceptado: 15 de setembro de 2020

Resumo. O obxectivo deste traballo é o de salientar a importancia que tivo a memoria dos e das protagonistas no traballo de investigación sobre o volframio na mina de Varilongo, no concello de Santa Comba (Blanco Ramos 2016). Ante a ausencia de fontes escritas, foi a memoria dos traballadores e traballadoras da mina a que encheu as lagoas daquel universo mineiro durante a Segunda Guerra Mundial.

Palabras chave: memoria; volframio; Varilongo; "roubeta"; contrabando.

\section{[es] La memoria de la mina de Varilongo (Santa Comba)}

Resumen. El objetivo de este trabajo es el de resaltar la importancia que tuvo la memoria de los y de las protagonistas en el trabajo de investigación sobre el volframio en la mina de Varilongo, en el ayuntamiento de Santa Comba (Blanco Ramos 2016). Ante la ausencia de fuentes escritas, fue la memoria de los trabajadores y trabajadoras de la mina la que ha llenado las lagunas de aquel universo minero durante la Segunda Guerra Mundial.

Palabras clave: memoria; volframio; Varilongo; "roubeta"; contrabando.

\section{[en] The Memory of the Varilongo Mine (Santa Comba)}

Abstract. The objective of this work is to emphasize the importance of memory of the protagonists in the research work on tungsten in the Varilongo mine, in the Santa Comba town hall (Blanco Ramos 2016). Faced with the absence of written sources, it was the memory of the workers who filled the different gaps during World War II.

Keywords: Memory; Tungsten; Varilongo; "roubeta"; Smuggling.

Sumario. 1. Introdución. 2. A expropiación das terras. 3. O rol da muller na mina e na vida familiar. 4. Loita, persecución e morte. 5. A participación da empresa no mercado negro. 6. Os nenos e as nenas mineiras. 7. Presos políticos. 8. A memoria cantada. 9. Conclusións. 10. Referencias bibliográficas.

Como citar: Blanco Ramos, C. (2020): “A memoria da mina de Varilongo (Santa Comba)”, en Madrygal. Revista de Estudios Gallegos 23 Núm. Especial, pp. 27-33. 
A memoria é un sol desenterrado que nos ceiba da noite, que regresa - ave fénix-da cinza e atravesa de luz a escuridade do pasado.

(Víctor Campio)

\section{Introdución}

Varilongo foi para os alemáns e os estadounidenses unha constante preocupación na súa estratexia bélica durante a Segunda Guerra Mundial (Hayes 1946: 271). As minas do couto mineiro de Santa Comba convertéranse no centro neurálxico da negociación sobre o mineral clandestino $^{2}$. Co contrabando de volframio, o goberno español melloraba substancialmente a balanza comercial do país e contribuía a liquidar a débeda que a España de Franco mantiña coa Alemaña de Hitler desde a Guerra Civil (Tussell 1995: 510).

Se outras minas de Galicia (Fontao e Lousame) serviron de escenario a escritores e investigadores, as de Santa Comba, a pesar de seren as minas máis importantes en produción de volframio (entre 1942-1963), carecían dun narrador e dun mínimo estudo.

Ante a falta de documentos específicos sobre a mina de Varilongo, foron as fontes orais as que romperon o silencio. Rescatamos desde abaixo as voces das mulleres, homes e nenos que da noite para a mañá se converteron en improvisados mineiros, ben da roubeta ${ }^{3}$ ou da empresa que, como dicía Ramón de Valenzuela Otero (1980: 78), era a máis ladra de todas. Durante o tempo da roubeta empezou a chegar xente de todas as partes de Galicia e doutros puntos de España. Os aventureiros de Buño, con experiencia en Monte Neme (Carmona Badía 2003: 274) xa traían as súas canaletas e os compradores furtivos, coa romana ao ombro, percorrían o monte comprando mineral. Naqueles primeiros meses de 1942 Varilongo era un enxame de homes, mulleres e nenos escaravellando na terra que vendían o seu traballo ao que mellor pagase. Non había patrón ata a "toma" dos montes de Varilongo pola Compañía Minera Celta, S.A.

Para falar dos baleiros neste artigo fixen unha selección dos e das informantes que cito a continuación, de acordo coas súas experiencias vividas e segundo os seus relatos orais dende a memoria: Manuel Antelo Suárez, Herminio Brenlla Mourelle, Carmen Caamaño Gómez, Manuel Espasandín Vilarnovo, María Josefa Gerpe Suárez, Eduardo Liste Carro, Eliseo Mourelle Rial, Concepción Mouro Rodríguez, Manuel Negreira Mouro, Dolores Pazos Varela, Sara Mata Mouro e Isolina Varela González.

A memoria dos e das informantes encheu as lagoas e reconstruíu aquela época na que a mina de Varilongo foi moi importante para a economía familiar das xentes dos lugares próximos ao couto mineiro da zona Coristanco-Santa Comba.

\section{A expropiación das terras}

A Compañía Minera Celta ${ }^{4}$ comezou as expropiacións e, en menor medida, a compra dos terreos a partir de maio de 1942. Sobre esta cuestión as fontes escritas afirman que foron os propietarios (Estadística Minera y Metalúrgica de España) os que impuxeron os prezos. Os donos das terras viviron estes acontecementos de maneira diferente, pois algúns foron obxecto de acoso por parte da empresa para que abandonasen as leiras. Asoballados e maltratados, non podían entender que un día, ao levantarse, as súas terras xa non lles pertencían.

Sara Mata Mouro (79 anos, do lugar de San Salvador), orfa de pai e nai, criouse con seis irmáns na casa dos avós paternos. Tiña doce anos cando andaba cun martelo polo monte en busca das pedras de volframio. Así nos relata un episodio do que foi testemuña:

2 Cómpre non esquecer que había personaxes importantes, tanto social como politicamente, relacionados co volframio en Galicia e grazas ao cal engordaron, se cabe máis, a súa fortuna. Podemos mencionar, entre outros, a José Martínez Ortego (conde Arguillo e pai de Cristóbal Martínez Bordiu), Joaquín Otero Goyanes (marqués de la Revilla), Ramón Serrano Suñer (ex ministro e cuñado de Franco) ou Demetrio Carceller (ministro de Industria e Comercio).

Unha forma de minería furtiva.

4 Nos primeiros meses de 1942, despois dun período completamente informal, en Varilongo, instalouse a Compañía Minera Celta S.A., empresa pertencente ao Grupo Fierro de Madrid, propiedade do banqueiro Ildefonso Fierro, home moi achegado a Franco. Á fronte estaba o seu socio José Parga Moure, un arrieiro de viños moi coñecido en Santiago. 
As leiras tiñan donos pero non nos respectaron. Botáronse encima delas, e seguiron ata que se lles arrendou polo que eles quixeron. Nós tivemos un altercado con Parga Moure. Foramos parar ós seus obreiros que estaban traballando sen permiso na nosa leira. O Rivas ${ }^{5}$, colleu o coche e marchou a Santa Comba, decontado volveu a Garda Civil e nós tivemos que marchar. Pero un veciño enfrontouse aos gardas:

-Así que vostedes veñen defender a man armada aos que nos están asoballando!

O Garda Civil contestoulle:

—Nós vimos defender a quen nos busca.

- Pero nós pagamos a contribución. As leiras son nosas e vostedes axúdanlles a botarnos do noso.

Logo fomos a Negreira ao avogado Caamaño. Defendeunos ben. Co tempo déronnos $20 \mathrm{mil}$ pesetas daquela época.

Outros informantes podían traballar nas súas leiras pero non eran donos das súas colleitas. Concepción Mouro Rodríguez (83 anos, do lugar de San Salvador) empezou á roubeta con doce anos e verbalizounos aquel sentimento de impotencia:

Ao principio [na roubeta] viñan compradores e vendiámoslle-lo mineral alí, na nosa propiedade. Desde que chegou a empresa, traballamos na nosa leira; porén, estabamos obrigados a entregarllo o volframio ao dono da mina. Xa non podíamos traballar para nós.

Co medo, non todos se atreveron a defender os seus dereitos, debido ao poder dos donos da Compañía Minera Celta e, sobre todo, ao trato das autoridades en especial o da Garda Civil. Por iso algúns veciños non reclamaron as terras. Ese é o caso de Herminio Brenlla Mourelle, que deixou de traballar no millo e nas patacas aos 17 anos para ingresar na Compañía Minera Celta e sacar escombros dun filón.

Nós tiñamos leiras por Varilongo. Traballáronse facendo filóns. Non nos pagaron nada. Nós non protestábamos por moita ignorancia e medo, sobre todo, á Garda Civil e aos carabineiros.

\section{O rol da muller na mina e na vida familiar}

A muller galega do rural sempre se caracterizou por ter ao seu cargo, ademais dos labores da casa, os traballos do campo e a carga familiar dos fillos. Dolores Pazos Varela (92 anos, do lugar de Espasandín), traballadora na roubeta e na empresa, falounos da súa realidade:

Facían falla os cartos, miña nai coidábame os fillos, e eu ía para a mina. Naquela época o único ingreso era o meu diñeiro da mina. Na miña cuadrilla había máis mulleres ca homes. Todos os veciños marchaban pola mañá cedo coa súa saqueta ao lombo para a mina. As mulleres eran todas fortes. Os cartos da mina había moito onde metelos. Primeiro empecei á roubeta e despois na empresa como recuperadora. Con estes cartos comprei unha besta para traballar na terra... gabiar e tamén ía á mina a cabalo. Inda dei a luz no camiño, no monte de Rieiro á volta da mina. Viña enriba da egua, non me deu tempo de chegar á casa.

As mulleres na mina tiñan tarefas específicas destinadas a elas. Carmen Caamaño Gómez (83 anos, do lugar de Padreiro de Castriz) cóntanos como era o seu duro traballo:

As mulleres na Compañía dedicábanse sobre todo ao traballo no lavadoiro ou machucando as pedras cunhas pranchas de ferro coas mans. Moitas choraban porque lles sangraban. Había que machucar para separar o mineral bo do malo, despois peneirábase como se fose baruta. Por cada caixón machucado pagábannos cinco pesos. Despois xa viñeron outros inventos e botáronnos fóra.

Carmen Caamaño fala da importancia que tivo a mina para a economía familiar:

Co diñeiro da mina axudámoslle á nosa nai a pagar os bens. O mineral que collíamos vendiámolo a quen máis nos dera. Fun tres anos á roubeta. Na casa eramos nove persoas: cinco irmáns, tres tíos e miña nai. O noso pai morrera, os bens eran de arrendo, pagabámoslle con trigo. En Padreiro, menos catro casas, as demais eran todas de arrendo, traballando duro para pagar a renda, gracias á mina.

Recollemos tamén o testemuño de Isolina Varela González (92 anos, do lugar da Cova), traballadora da roubeta e da empresa:

Empecei facendo buratiños e sacando aquela terra e levándoa na canaleta. Tiña 20 anos. Daquela había moita diferenza nos cartos. Traballando na roubeta sacabamos 30 ou 40 pesos 
ao día, na empresa cinco pesos ao día. E ao xornal polas casas non se gañaba cinco pesos.

Na nosa casa eramos sete persoas (desas) dúas íamos á mina, porque as demais había que traballar na terra. Eu traballei na Braña de Varilongo. Tiña 8 anos cando empecei á escola. Non íamos sempre, á tarde nunca, porque tiñamos que traballar non sendo un día en que chovera moito. Traballabamos fóra nas leiras.

\section{Loita, persecución e morte}

$\mathrm{O}$ instinto de supervivencia nos tempos da fame da inmediata posguerra facía que as persecucións de carabineiros e da Garda Civil se convertese nunha verdadeira loita diaria. Algúns non tiveron sorte coma o mozo Antonio Gerpe Soto, morto a tiros pola Garda Civil na costa do alto de Rial en xuño de 1942. Non foi o único. Así o recorda Manuel Espasandín Vilarnovo (do lugar de Santa Sabiña) que traballou na roubeta (e veciño daqueles montes):

Na chousa de Varilongo, na propia mina mataron a un home dun tiro no peito polos carabineiros. Ninguén reclamou o seu corpo. Estaba badurnado en sangue, non sei como se enterrou, porque non tiña certificado (eu velei toda a noite o corpo na caseta do cemiterio de Santa Sabiña). Os veciños xuntaran cartos para mercarlle o cadaleito e o cura botoulle os funerais sen cobrar.

As persecucións da Garda Civil e dos carabineiros era o verdadeiro terror desde o intre en que pisaban o monte. De aí o suborno aos carabineiros e á Garda Civil, feito que todos coñecían e do que ninguén falaba. Para Sara Mata Mouro, ese anaco de memoria inda está moi fresca:

Había que correr porque había tiros. No Vilardante, os gardas viñan tras un pai e un fillo. $\mathrm{O}$ fillo escapou e ao pai pegáronlle un tiro. Despois os gardas levárono ao pallal. $\mathrm{O}$ cura fora confesalo e dispuxo da súa vida. Morreu. Aquel crego chamoulles asasinos aos gardas, que non había lei de matar a unha persoa que viña do monte... que non viña de roubar.

María Josefa Gerpe Suárez (93 anos, do lugar da Ponte), traballadora da roubeta e da empresa, relátanos como sufriu unha persecución:
Chegamos a Grixoa e os carabineiros do Coristanco atrás nosa. Abancamos o río, as pontes do Xallas. Cando chegamos a Rieiro non podíamos máis de correr. Eramos cinco ou seis. Eu tiña unha bolsa chea de mineral apañado na Compañía. Corriamos. Naquel momento pasaba un carro de mato, eu engancheime nun fungueiro detrás da roda, pero o medo gardaba que viña detrás. Os carabineiros colleron a unha compañeira da Xesteira, pegaron nela, eu arrebolei a bolsa ao medio do monte. Alí, entre o mato con fieitas, anicámonos. Un dos carabineiros seguiu pola beira do río. Eu morría alentada de correr. Os outros puxéronse no alto buscándonos. Dixen:

—Non alentedes, que están aí.

Cansáronse e deron volta (...). Cheguei á casa sangrando polas pernas. Viña tollida de correr por riba dos toxos.

A garda Civil non respectaba os fogares nin as familias, entraba de maneira aleatoria nas casas e buscaba nos lugares insospeitables. Así dá conta Sara Mata Mouro dunha das súas experiencias:

Se cadra viñan os gardas, entraban pola porta do curral e saían pola eira. Un día metéronse tamén na cociña e a un coñecido noso mallárono aquí [cociña].

Un irmán da miña nai era de Suevos. Moitos da zona paraban aquí en San Salvador, na nosa casa, ás veces para esconderse dos gardas. Unha vez, estes entraron dentro da casa a buscar a Rogelio da Baña, déronlle unha vareada. O meu avó, que andaba con bastón (tiña 80 anos), chamoulle a atención á Garda Civil.

- Coidadiño, dentro da miña casa non se lle pega a nadie!

Pegaban coa culata do fusil. Outra vez entrou unha muller correndo na casa, meteuse dereita á cociña. Díxome:

-Miña neniña, dille que son túa nai!

Colleu o coitelo e púxose a rascar as patacas, porque, se non, tamén podían mallar en nós.

\section{A participación da empresa no mercado negro}

A empresa complementaba o sistema de explotación pseudorregular con outro sistema "irregular" destinado a evadir os controis do COMEIM $^{6}$. Este sistema permitía a mineiros

6 Consejo Ordenador de Minerales Especiales de Interés Militar. Organismo creado en 1941, para acabar coa explotación irregular e co contrabando. 
independentes ("destajistas" e "recuperadores") traballar polo monte, dentro do perímetro da concesión mineira, coa obriga de entregar o mineral á empresa ${ }^{7}$. O "destajista" era patrón e responsable dos seus obreiros.

Os "recuperadores" eran coñecidos por "brigadas" porque ían en grupo de catro ou cinco. Todos socios a partes iguais, tamén estaban obrigados a vender o mineral recollido á empresa. Este sistema permitíalle a esta non declarar ao COMEIM o mineral recollido polos mineiros independentes. Por conseguinte, o volframio non declarado entraba no mercado negro ${ }^{8}$.

Evaristo Suárez Gerpe (81 anos, do lugar das Antes) entrou a traballar na compañía con 13 anos e conta o que viviu día a día:

Os primeiros que roubaban eran os donos das empresa. Nós tiñamos unha taberna nas Antes, a taberna do Barroso. Meu pai era amigo do "Rivas", porque el tiña un almacén de viños. Levaba o viño co camión polas tabernas, así coñeceu a meu pai e díxolle:

— Ti compra, que despois eu págoche

Dunha vez gañamos seis mil pesetas xuntas. Nós comprabamos aos da roubeta para Rivas. Despois viñas a buscalo desde a Picota e outros sitios. Os transportistas viñan con carros de vacas [...] na taberna fixemos un burato, coma un soto pequeno, onde cabía unha hucha para meter o mineral.

\section{Os nenos e as nenas da mina}

A utilización de poboación infantil como man de obra barata foi unha constante en todas as zonas mineiras durante a etapa do conflito bélico internacional. Son demasiados os informantes que, entre os sete ou trece anos, xa traballaban na mina para entregar o que gañaban na casa. Evaristo Gerpe Suárez foi un daqueles rapaces que desempeñaban o traballo dun adulto:

Empecei a traballar con 13 anos. Íamos campo a través, cando viñan os gardas botábannos fóra. Logo, como meu pai tiña amizade con Rivas, fomos para a Braña de Varilongo. Eu axudaba a poñer barrenos.

Eliseo Mourelle Rial (84 anos, do lugar de Boaña de Castriz), que, con só dez anos, nego- ciou a súa primeira pedra de volframio por 24 pesetas, fai memoria do seu primeiro día nos montes de Varilongo:

Ao outro día da noticia fun con outro rapaz do lugar ao monte. Decontado atopei nun valado unha pedra negra que pesaba moito. Por alí todo o mundo picaba. Eu miraba a pedra entre as miñas mans, cando pasou un señor.

—Rapaz!, canto queres pola pedra?

Pedinlle 30 pesetas. Eu inda non sabía que clase de pedra era. Ao final tratámola en 24 pesetas. Isto foi nos penedos de Grixoa de Esternande (...). Ao día seguinte, cando chegou o cura de Cances e un home que lle chamaban o Avelenda de Carballo, o monte xa estaba cheo de xente. Estes empezaron a tiros, pero, como a xente era tanta e o monte moi grande, non facían nada. En canto eles marchaban a xente volvía. Eu era un deles (...) levaba unha bolsa de estopa que me fixeran na casa e un martelo de carpinteiro de dúas golas. Estabamos a picar e a buscar filóns, sacándolle os terróns de arriba.

Había pedras tiradas polo monte, apañabas as que podías, pero deseguida volvía a batida de Avelenda máis a do cura. Este, coa sotana e o tricornio, tirando tiros coma un poseso detrás da xente, non paraba de berrar:

-Alto, rapaz, que te mato!

Sentías as balas, pero o rapaz non tirou a bolsa. Non tiraban a matar, senón para que marcharamos, pero, cando acababan as balas, os que marchaban eran eles.

Anos máis tarde, Eliseo Mourelle Rial tamén empregou a outros nenos:

Nos lavadoiros había moitos rapaces traballando de 7 a 10 anos. Non ían á escola e querían comer. Eu cheguei a ter 16 rapaces traballando comigo. O primeiro que fixen foi levalos a comer á cantina. Claro que eu daquela tiña 17 anos e xa me convertera en destajista.

\section{Presos políticos}

Durante a Segunda Guerra Mundial, debido á cantidade de presos políticos en Galicia, os penais funcionaron como meros provedores da man de obra barata para os donos das explotacións mineiras. Agora ben, en Varilongo, quizais debido ao descubrimento serodio das

Remunerado o quilo a 15 pesetas.

8 Dende que os estadounidenses colaboraron cos británicos na compra do mineral (mediados de 1941 ata xullo de 1943), a loita pola compra de volframio foi moi disputada entre alemáns e aliados. Cómpre saber que os aliados chegaron a pagar ata 243 pesetas por quilo de volframio no mercado negro. 
minas, non houbo un destacamento penal como no caso de Silleda. Había presos políticos que tiñan que pasar revista no cuartel; tamén había republicanos camuflados que lograron escapar e que utilizaron a mina como refuxio ou como medio para sobrevivir.

Igualmente se utilizaba a mina como fonte de ingresos para axudar a outros camaradas tal e como recolle a historiadora Aurora Marco (2011: 497) de Carmen Balboa:

Teresa Lorenzo tiña relación co grupo comunista compostelán, como tamén o seu home, José Vázquez Miguez, que traballaba no concello de Santiago e era o encargado de facer chegar aos presos do cárcere compostelán cantidades de diñeiro que reunían para este fin traballadores de volframio de Santa Comba e Silleda.

Hai que salientar neste contexto o bar Vilas, no Camiño Novo de Santiago de Compostela, que era o lugar frecuentado por aqueles que fuxían das poutas franquistas. O dono, Andrés Porto, foi un home moi receptivo con estas persoas. Por outra banda, Parga Moure, un dos donos da mina, vivía na mesma rúa e paraba a miúdo no bar, de aí que lle dese traballo na mina a moita xente de Santiago sen importarlle as súas ideas políticas. Foi o caso de Eduardo Liste Forján, xefe de vixilantes de Varilongo que fora perseguido por comunista e por ser irmán de Enrique Líster.

Así opinaba Eliseo Mourelle Rial, aquel rapaz que realizou o seu soño con dez anos e que comprou a mina no ano 1991:

Os vixilantes, a maioría, eran do Partido Comunista. Uns estaban presos, outros saían do cárcere. Franco mandounos traballar á mina, pero esa xente tiña máis escola ca nós. Sabían facer os partes dos obreiros, por iso os metían de encargados de almacén ou de vixilantes. Algúns por desconfianza eran obrigados a pasar lista cada mes no cuartel da Garda Civil. O xefe de vixilantes era compadre meu, chamábase Eduardo Liste Forján.

Eduardo Liste Carro do lugar de Ameneiro, sobriño do xefe de vixilantes (Eduardo Liste Forján), traballou desde moi novo na mina da man do seu tío e sabía moi ben do que non se podía falar:

Alí na mina, había escondida un montón de xente republicana. Eu coñecín a Luís Hernández
Vitorelo, asturiano, e parece ser que fora tenente republicano en Asturias. Outro chamábase Ceferino, encargado das separadoras ${ }^{9}$ do mineral en Santiago. Eu xa marchara de Varilongo, daquela traballaba nun taller mecánico, pero volvín atoparme con Ceferino e foi cando me dixo:

-Eduardo! O meu nome non é Ceferino. A ti pódocho dicir. Ese era o nome que utilizaba na mina (...).

"De política non se falaba", era a frase que estaba marcada a lume e ferro nas cabezas da xente. Frase que repetiron, sen excepción, todos os informantes e que remataba con outra: "Ías dereito á cadea". Os campesiños tiñan asumido que a política era un tema tabú, tal e como lembra Manuel Negreira Mouro:

Sabíamos que había presos políticos. Un era Eduardo Liste, había máis da súa zona. Manuel, o seu irmán, era case coma nós. Falaba connosco. Era bo compañeiro.

Aquí viñeron xente da zona roja, escapados... Pero silencio absoluto. Os que axudaban aos Foucellas ían á cadea. Por aquí ían de paso. A xente, ao velos vir, pechaba as casas.

Isolina Varela González di que non oíra falar de política nin sabía para onde ía o mineral:

De política non lle oín falar a ninguén, se falaban os "grandes" era cando non oíamos nós. Non había política ningunha. Alí só traballar. Nós non sabíamos que había presos políticos, sabíamos que o Eduardo Liste estivera na cadea. Manolo, o irmán, creo que non, pero o do Eduardo sabíao todo o mundo.

\section{Memoria cantada}

Grazas á memoria das nosas informantes puidemos recoller trece cantareas cuxa temática corresponde ao sector mineiro do lugar de Varilongo. No seu día eran cantadas polas traballadoras da mina, mulleres xenerosas que non dubidaron en compartir connosco os seus recordos. Cómpre saber que a voz cantada foi unha constante no mundo rural e como apunta Blanco Pérez (1994:16) a función destas "cantas", aceptada socialmente, era a de divertir, ensinar, ridiculizar, aturar o traballo e, sobre todo, establecer lazos de unión entre as traballadoras.

As composicións son estrofas de catro versos, sen medida rigorosa debido ás alteracións

9 Refírese ás separadoras clandestinas que tiña Parga Moure en Santiago. 
que sofren na transmisión oral. Unha imperfección común na poesía popular.

Podemos dicir que as cantareas non están mortas, grazas á voz e á memoria das nosas informantes e agora na escrita superan as barreiras do tempo. Segundo a liña temática clasificamos as cantareas recollidas en catro grupos: de amor, de traballo, de lugares e de burla. A continuación ofrecemos unha mostra.

\section{Amor:}

A mina de Varilongo mina negra pa min, entrei sen amores nela, namoradiña saín.

Traballo:

No alto de Varilongo lo primero que se ve catrocentas canaletas e a xente a correr.

\section{Lugares / sátira:}

$$
\begin{aligned}
& \text { Adiós Costa do Cuso, } \\
& \text { amais a de Brandomil, } \\
& \text { é onde queda o diñeiro, } \\
& \text { e máis a Guardia Civil. }
\end{aligned}
$$

Burla:

$$
\begin{aligned}
& \text { Os guardias na Braña, } \\
& \text { e nós d'arredor, } \\
& \text { démoslle a farsa } \\
& \text { por San Salvador. }
\end{aligned}
$$

\section{Conclusións}

Sen a memoria dos vinte e tres informantes aos que entrevistei persoalmente, algúns en repetidas ocasións, o libro $O$ volframio en Varilongo. Santa Comba de Xallas (1941-1963) non vería a luz. Foron os recordos agochados na memoria os que narraron, non soamente os traballos e os días da mina, senón a forma de vida dunha sociedade rural de posguerra (sempre unha visión concentrada en cada relato persoal $)^{10}$. Sabemos que a memoria é o presente do pasado pero que tamén dalgunha maneira é a continuidade temporal destes vinte e tres informantes.

\section{Referencias bibliográficas}

Aróstegui, Julio (2004): La Historia vivida. Sobre la historia del presente. Madrid: Alianza.

Blanco Pérez, Domingo (1994): Historia da Literatura Popular Galega. Santiago de Compostela: Universidade de Santiago de Compostela, Servizo de publicacións.

Blanco Ramos, Carmen (2016): O volframio en Varilongo. Santa Comba de Xallas (1941-1963). Vigo: Xerais.

Carmona Badía, Joan (2003): "La minería española de wolframio, 1936-1945: los años de la fiebre", en G. Sánchez Recio e J. Tascón Fernández (coords.), Los empresarios de Franco: política y economía en España 1936-1957. Barcelona: Crítica, pp. 261-280.

Catalán, Jordi (1995): La economía española y la Segunda Guerra Mundial. Barcelona: Ariel.

Forcadell Álvarez, Carlos (2004): Usos de la historia y política de la memoria. Zaragoza: Prensas Universitarias de Zaragoza.

Hayes, Carlton J. H. (1946): Misión de guerra en España. Madrid: Ediciones y publicaciones españolas.

Hoare, Samuel (1977): Embajador ante Franco en Misión Especial. Madrid: Sedmay.

Marco, Aurora (2011): Mulleres na guerrilla antifranquista galega. Bertamiráns/Ames: Laiovento.

Ricoeur, Paul (1999): La lectura del tiempo pasado: Memorial y olvido. Madrid: Arrecife Producciones.

Rodríguez Teijeiro, Domingo (2010): Presos e prisións na Galicia de guerra e posguerra: 1936-1948. Vigo: Galaxia.

Tussell, Javier (1989): La España de Franco: el poder, la oposición y la politica exterior durante el franquismo. Madrid: Historia 16.

- (1995): Franco, España y la II ${ }^{a}$ Guerra Mundial. Madrid: Temas de Hoy.

Valenzuela Otero, Ramón (1980): Era tempo de apandar. Madrid: Akal.

10 Por outra parte, recuperamos documentos gráficos que con moito interese buscaron nos seus faiados da vida. 